\title{
Nano-Structured Ceramics by Gas-Phase Reaction
}

\author{
C. M. Carney, S. A. Akbar \\ Department of Materials Science and Engineering, The Ohio State University, Columbus, \\ Ohio 43212, USA

\begin{abstract}
Single-crystalline nanofibers of tin dioxide $\left(\mathrm{SnO}_{2}\right)$ were synthesized by a gas-phase reaction of solid $\mathrm{SnO}_{2}$ sintered disks in a reducing atmosphere between 700 and $800{ }^{\circ} \mathrm{C}$. The resulting nanostructures grew on regions of the disk that were coated with gold, which acted as a catalyst. The samples were analyzed with scanning electron microscopy, x-ray diffraction, and transmission electron microscopy. The nanofiber length was controlled by varying the reaction time and by the sintering agent used to densify the $\mathrm{SnO}_{2}$ disks.
\end{abstract}

\section{Introduction}

The ability to modify their electrical, optical, magnetic and chemical properties by varying their cation valence or anion occupancy make functional oxides such as stannic oxide $\left(\mathrm{SnO}_{2}\right)$ attractive materials for fabrication of smart devices (1). Recently, lowdimensional nanostructures such as nanobelts (2-8) and nanowires $(4,6,9-12)$ of functional oxides have become the focus of intense research due to their fundamental physical properties and their potential for integration into devices such as field effect transistors and sensors $(2,6,12-15)$. One of the most common ways to produce large quantities of nanostructures is with vapor phase synthesis. Because of the high vapor pressure of their oxides, nanostructures of $\mathrm{ZnO}, \mathrm{MgO}, \mathrm{SiO}_{2}, \mathrm{In}_{2} \mathrm{O}_{3}$, and $\mathrm{SnO}_{2}$ are commonly produced using this method $(3,4,9,10,11,16-18)$. A special case of vapor phase processing is vapor-liquid-solid (VLS) growth that utilizes a liquid metal catalyst that acts as a collector of evaporated gas species (19). $\mathrm{SnO}_{2}$ nanostructures grown with Au-assisted VLS start with either $\mathrm{Sn}$ or $\mathrm{SnO}$ precursors (usually in an $\mathrm{Ar}$ or $\mathrm{Ar} / \mathrm{O}_{2}$ environment) because fast growth can be obtained between 850 and $1080{ }^{\circ} \mathrm{C}$, while thermal evaporation of $\mathrm{SnO}_{2}$ requires temperatures greater than $1300{ }^{\circ} \mathrm{C}(15,18)$. The resulting nanostructures are produced on a Au-coated substrate downstream where they grow in a random fashion. The morphology of the structures is controlled by the properties of the carrier gas, the temperature, precursor material, and the size of the gold particle used to initiate growth.

This paper describes a method to grow nanofibers using a $\mathrm{SnO}_{2}$ sintered body that is both the precursor and the substrate for nanofiber formation. Instead of an inert gas such as $\mathrm{Ar}$, a mixture of $5 \% \mathrm{H}_{2}$ balance $\mathrm{N}_{2}$ gas is used to etch the $\mathrm{SnO}_{2}$ disk at a moderate temperature $\left(720^{\circ} \mathrm{C}\right)$ and the resulting nanofibers are grown in regions of the sample coated by gold. The location and the lengths of the fibers can be controlled by controlling the processing parameters such as the dopant in $\mathrm{SnO}_{2}$; the processing temperature and time; and the gold coating. 


\section{Experimental}

$\mathrm{SnO}_{2}$ nanostructures have been synthesized by catalyst-assisted thermal evaporation of Au-coated $\mathrm{SnO}_{2}$ disks. Commercial $\mathrm{SnO}_{2}$ (Cerac, 99.9\% pure) and $\mathrm{CoO}$ (Cerac, 99.5\% pure) powders were used. $\mathrm{SnO}_{2}$ was doped with $5 \mathrm{wt} \% \mathrm{CoO}$ by ball milling the powders with yttria-stabalized zirconia grinding balls in isopropanol for at least 6 hours. The powders were then dried and compacted into disks under uniaxial pressure of 1 ton in a stainless steel die by single-end compaction. The compact disks were sintered in an air atmosphere at $1300{ }^{\circ} \mathrm{C}$ for 24 hours to obtain dense polycrystalline samples. The samples were then coated with gold using a template with $2 \mathrm{~mm}$ circular openings. The Au-coated $\mathrm{SnO}_{2}$ disks were heated in a $2.5 \mathrm{~cm}$ diameter quartz tube in a horizontal tube furnace between 700 and $800{ }^{\circ} \mathrm{C}$ for times ranging from 2 to 6 hours. During heating a mixture of $5 \% \mathrm{H}_{2}$ balance $\mathrm{N}_{2}$ flowed over the sample at a rate of $1 \mathrm{~L} / \mathrm{min}$. Reduction of the sample to metallic tin is suppressed by bubbling the $\mathrm{H}_{2} / \mathrm{N}_{2}$ mixture through room temperature water before it enters the reaction tube. The samples were then analyzed by field emission scanning electron microscopy (ESEM, Phillips XL-30), X-ray diffraction (XRD, Phillips XDS-2000), and transmission electron microscopy (TEM, FEI CM200) to determine the structure and chemistry of the resulting structures.

\section{Results and Discussion}

\section{Morphology of the Fibers}

SEM analysis shows two regions of $\mathrm{SnO}_{2}$ fiber growth, each with a different morphology. A diagram of the sample is shown in Figure 1a. The boundary region between the $\mathrm{Au}$-coated and uncoated $\mathrm{SnO}_{2}$ shows growth of long thin nanofibers that are randomly oriented. The fibers are on the order of 20 to 40 nanometers in diameter and several hundred microns long. The area density of fibers in the boundary region increases with the growing time and the amount of uncoated $\mathrm{SnO}_{2}$. A representative image of these fibers is shown in Figure 1.a. Experiments conducted at lower temperatures and shorter times to capture initial growth show that nanofiber growth only initiates in regions that are coated in gold.

Approximately 100 to 200 microns from any uncoated portion of $\mathrm{SnO}_{2}$, nanofibers primarily grow perpendicular and parallel to the substrate surface. The diameters of these fibers range from 100 to 200 nanometers with lengths ranging from a few nanometers up to 10 microns (Figure 1.c.) The number of the fibers grown per area in this region is less than in the boundary region. The diameters do not appear to depend on the temperature or reaction time; however, the fibers will grow longer with increased reaction time. Invariance in nanofiber diameter with temperature and time leads to the conclusion that the nanofiber diameter is controlled by the size of the gold particle catalyzing growth $(6$, $12,13)$.

The final morphology of the structures is influenced by the temperature, the gas flow parameters, and the reaction duration. The reaction duration and temperature were varied systematically to determine the optimum condition for nanofiber growth to be a 2 to 4 hour anneal at $720{ }^{\circ} \mathrm{C}$ in $5 \% \mathrm{H}_{2}$ balance $\mathrm{N}_{2}$. If the temperature is increased above $760{ }^{\circ} \mathrm{C}$, 

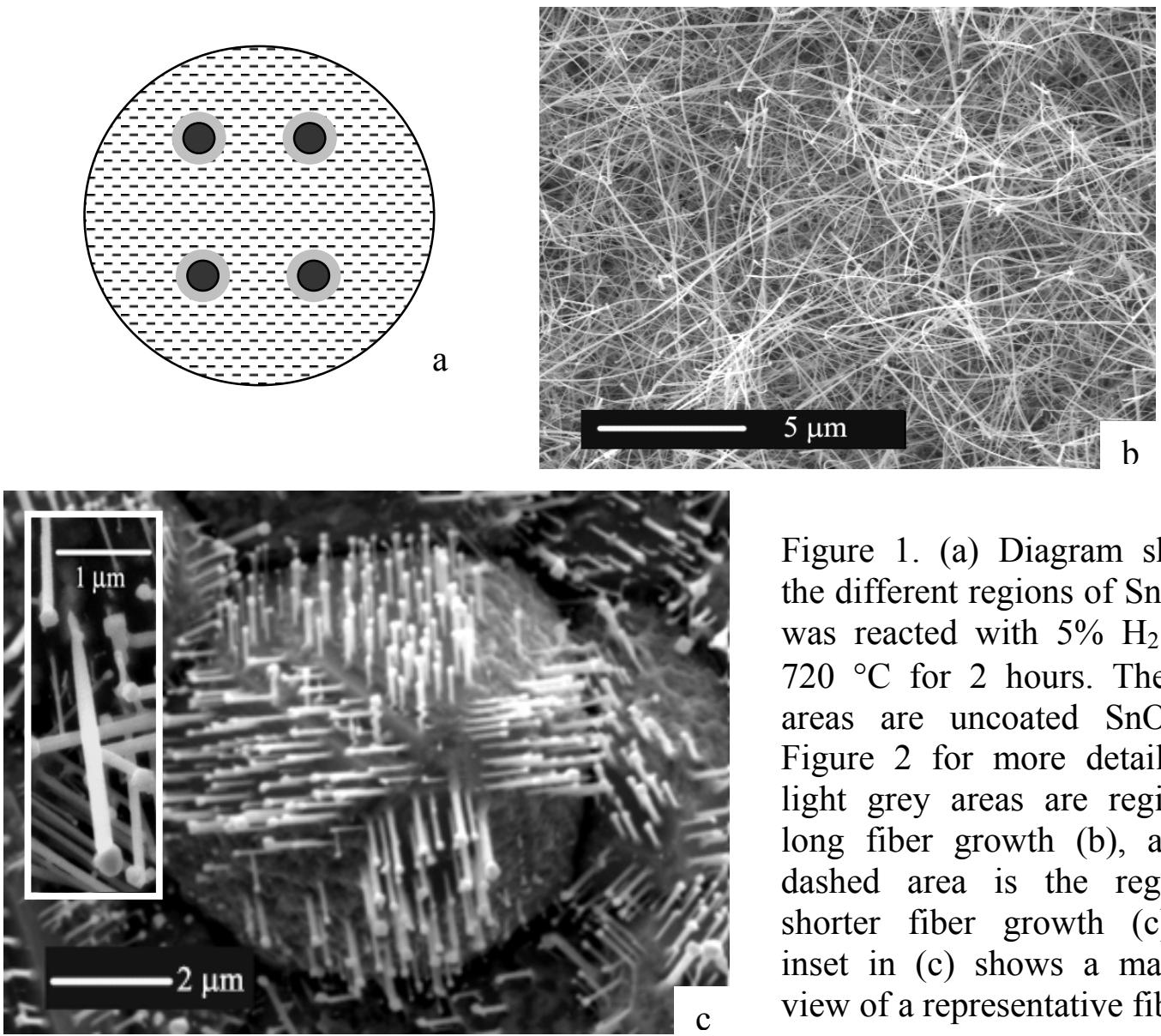

Figure 1. (a) Diagram showing the different regions of $\mathrm{SnO}_{2}$ that was reacted with $5 \% \mathrm{H}_{2}$ gas at $720{ }^{\circ} \mathrm{C}$ for 2 hours. The black areas are uncoated $\mathrm{SnO}_{2}$ (see Figure 2 for more details), the light grey areas are regions of long fiber growth (b), and the dashed area is the region of shorter fiber growth (c). The inset in (c) shows a magnified view of a representative fiber.

massive reduction of the sample to metallic tin occurs while temperatures below $680{ }^{\circ} \mathrm{C}$ showed no fiber growth. Increasing the temperature between 720 and $760{ }^{\circ} \mathrm{C}$ produced a larger number of the longer random nanofibers per sample area. The optimum time for oriented fiber growth was between 2 and 4 hours with longer times producing a larger proportion of the longer and less oriented structures. Decreasing the flow below 800 $\mathrm{mL} / \mathrm{min}$ drastically decreased the number of fibers that were grown per area. Additionally, when the samples were subjected to the same temperatures in pure $\mathrm{N}_{2}$ no nanofiber growth resulted, suggesting the necessity of a reducing gas such as $\mathrm{H}_{2}$ for the growth of nanofibers from $\mathrm{SnO}_{2}$ precursors at low temperatures $\left(<800{ }^{\circ} \mathrm{C}\right) . \mathrm{H}_{2}$ has been shown to reduce thin films of $\mathrm{SnO}_{2}$ to oxygen deficient $\mathrm{SnO}_{2-\mathrm{x}}$ at temperatures as low as $380{ }^{\circ} \mathrm{C}(20,21)$ through reaction [1].

$$
\mathrm{SnO}_{2}(\mathrm{~s})+\mathrm{H}_{2}(\mathrm{~g}) \rightarrow \mathrm{SnO}_{2-\mathrm{x}}(\mathrm{s})+\mathrm{xH}_{2} \mathrm{O}(\mathrm{g})
$$

However, if the process continues, $\mathrm{SnO}_{2}$ will be reduced to $\mathrm{SnO}$, but $\mathrm{SnO}$ is thermodynamically unstable at temperatures above $300{ }^{\circ} \mathrm{C}(10,21)$ leading to reaction [2].

$$
2 \mathrm{SnO}(\mathrm{g}) \rightarrow \mathrm{SnO}_{2}(\mathrm{~s})+\mathrm{Sn}(\mathrm{l})
$$


When there is no gold coating and the samples are subjected to the same processing conditions, no nanofiber growth is seen on the sample. However, in the regions of goldcoated samples that are left uncoated, etching of the grain boundaries and the bulk of the grains is seen (Figure 2.a-b.). Experiments were conducted to collect the by-products of the reaction between $\mathrm{H}_{2}$ and $\mathrm{SnO}_{2}$. The nanofibers that are formed downstream are shown by XRD to be rutile $\mathrm{SnO}_{2}$ proving that both tin and oxygen are removed from the surface as suggested by equation [1]. This is consistent with other experiments that advance a self-catalyzed growth model of $\mathrm{SnO}_{2}$ nanofibers (9). Figure 2.c. shows the nanofibers that are collected downstream from the reaction.
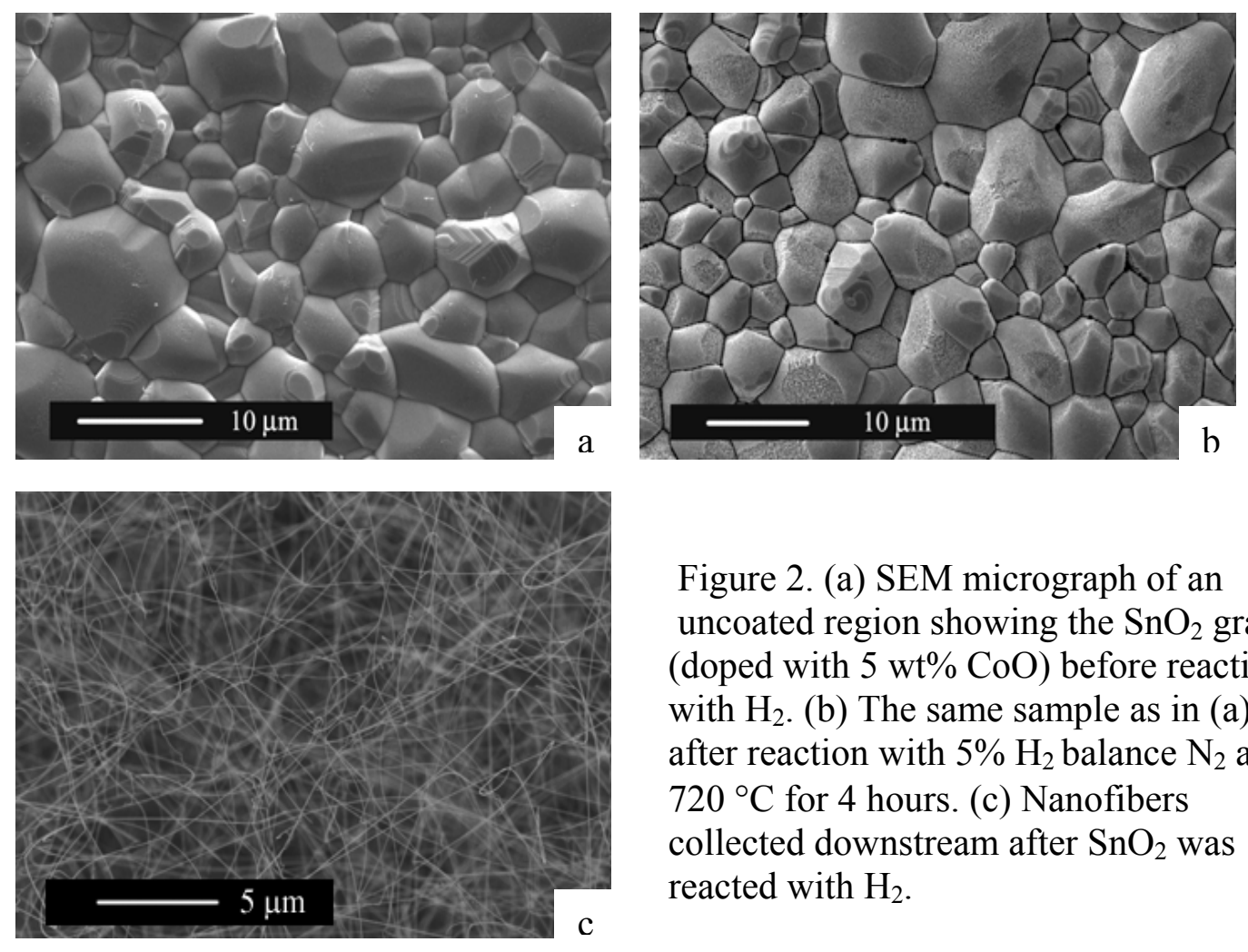

Figure 2. (a) SEM micrograph of an uncoated region showing the $\mathrm{SnO}_{2}$ grains (doped with $5 \mathrm{wt} \% \mathrm{CoO}$ ) before reaction with $\mathrm{H}_{2}$. (b) The same sample as in (a) after reaction with $5 \% \mathrm{H}_{2}$ balance $\mathrm{N}_{2}$ at $720{ }^{\circ} \mathrm{C}$ for 4 hours. (c) Nanofibers collected downstream after $\mathrm{SnO}_{2}$ was reacted with $\mathrm{H}_{2}$.

\section{Chemistry and Crystal Structure of the Fibers}

The XRD pattern of the nanofibers from the $\mathrm{SnO}_{2}$ surface is shown in Figure 3.b. All the main peaks can be indexed according to the tetragonal rutile structure of $\mathrm{SnO}_{2}$. Peaks corresponding to tetragonal tin and cubic gold are also seen. The observed tin is a product of the reduction of the $\mathrm{SnO}_{2}$ by $\mathrm{H}_{2}$ (equations 1-2) and the gold peak is from the metal that was deposited on the sample to catalyze the growth of the nanofibers.

The SEM images indicate that the fibers are composed of a tip and a body. Figure 3.a. is a TEM bright-field image of a single $\mathrm{SnO}_{2}$ nanofiber collected after sonication of the sample in water. The selected area electron diffraction (SAED) pattern in the inset of Figure 4 shows the fiber to be a single crystal of $\mathrm{SnO}_{2}$. The SAED pattern was taken 
with the electron beam perpendicular to the fiber edge. Energy-dispersive X-ray spectroscopy (EDS) of the fiber body indicates that there is only tin and oxygen present. Since the tip of the fiber is only composed of gold and the melting point of gold is not lower than $800{ }^{\circ} \mathrm{C}$ for particles $12 \mathrm{~nm}$ and larger (19), it is likely that the nanofiber growth is initiated by the gold particle and may continue through the adsorption of molecular species on the low-energy surface of the growing nanofibers. These adsorbed molecules could then diffuse to a low-energy state at the growth front (vapor-solid growth mechanism) $(12,22)$. The TEM results along with the XRD data show that the fiber is rutile $\mathrm{SnO}_{2}$ with a pure gold tip.
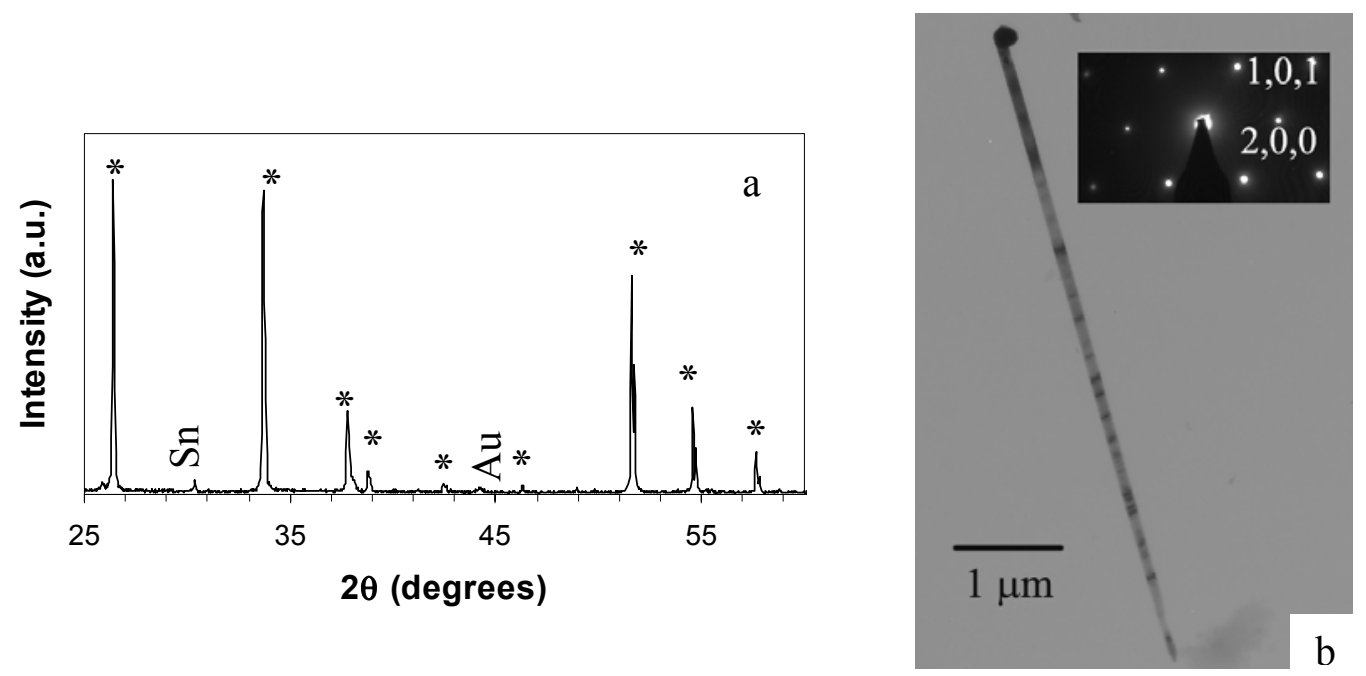

Figure 3. (a) XRD pattern confirming that the crystal structure of the nanofibers resulting from the reaction with $\mathrm{H}_{2}$ is rutile $\mathrm{SnO}_{2}$. All peaks can be indexed as tetragonal $\mathrm{SnO}_{2}$ (indicated by *) except the peaks from the gold coating and the metallic tin that is produced under $\mathrm{H}_{2}$ reduction. (b) TEM micrograph of an individual nanofiber shown with the SAED pattern (inset) taken perpendicular to the fiber edge along $[0,-1,0]$.

\section{Summary}

Single-crystalline $\mathrm{SnO}_{2}$ nanofibers were synthesized through a simple gas-solid reaction. The morphology of the products changed with processing temperatures and reaction times. The nanofibers were grown in selected regions on the same sintered body by using patterned gold deposition. The processing parameters could be controlled to produce nanostructures that were shorter and oriented with respect to the surface, or longer and randomly oriented.

Understanding the growth of $\mathrm{SnO}_{2}$ nanofibers is important both for studying fundamental properties of nanofibers and determining processing techniques that can lead to new nanofiber production methods for the creation of novel functional devices. One of the attractive features of the nanofibers reported in this work is that their lengths and 
locations can be tuned by the reaction times and the template used to deposit the gold. Additionally, a great number of the fibers are aligned vertically to the substrate surface, which could be critical to fabrication of functional devices. Although the fact that the fibers are grown on a $\mathrm{SnO}_{2}$ substrate may limit their usefulness as uniquely improved sensors, other applications such as energy storage or field emitters could be enhanced due to the enhanced surface area and directionality of the fibers. Work is being conducted to expand the technology to thin films.

\section{Acknowledgments}

This project was financially supported by the National Science Foundation through NSF-IGERT Grant \#0221678. The authors would like to thank Henk Colijn of the OSU CEOF for his assistance with the TEM analysis and Dr. K. Sandhage from Georgia Institute of Technology for his discussions.

\section{References}

1. Z. L. Wang and Z. C. Kang, Functional and Smart Materials, p. 7, Plenum, New York (1998).

2. J. Duan, S. Yang, H. Liu, J. Gong, H. Huang, X. Zhao, R. Zhang, Y. Du, J. Am. Chem. Soc. 127, 6180 (2005).

3. J. K. Jian, X. L. Chen, W. J. Wang, L. Dai and Y. P. Xu, App. Phys. A 76, 291 (2003).

4. L. Zhong and L. Wang, Adv. Mater. 15, 432 (2003).

5. J. Zhang, F. Jiang and L. Zhang, J. Phys. D 36, L21 (2003).

6. Z. Rong, D. Zheng, W. Pan and Z. Wang, Adv. Funct. Mater. 13, 9 (2003).

7. X. L. Ma, Y. Li and Y. L. Zhu, Chem. Phys. Lett. 367, 794 (2003).

8. J. Hu, Y. Bando, Q. Liu and D. Golberg, Adv. Funct. Mater. 13, 493 (2003).

9. B. Wang, Y. H. Yang, C. X. Wang and G. W. Yang, J. App. Phys. 98, 073520-1 (2005).

10. Y. Chen, X. Cui, K. Zhang, D. Pan, S. Zhang, B. Wang, J. G. Hou, Chem. Phys. Lett. 369, 16 (2003).

11. D. Calestani, M. Zha, G. Salviati, L. Lazzarini, L. Zanotti, E. Comini, G. Sberveglieri, J. Crystal Growth 275, e2083 (2005).

12. S. Mathur, S. Barth, H. Shen, J. -. Pyun and U. Werner, Small 1, 713 (2005). 
13. S. H. Lou, Q. Wan, W. L. Liu, M. Zhang, Z. F. Di, S. Y. Wang, Z. T. Song, C. L. Lin, J. Y. Dai, Nanotech. 15, 1424 (2004).

14. H. Huang, O. K. Tan, Y. C. Lee, T. D. Tran, M. S. Tse, X. Yao, App. Phys. Lett. 87, 163123-1 (2005).

15. J. H. He, T. H. Wu, C.L. Hsin, K. M. Li, L.J. Chen, Y.L. Chueh, L. J. Chou, Z. L. Wang, Small 2, 116 (2006).

16. E. Comini, G. Faglia, G. Sberveglieri, D. Calestani, L. Zanotti, M. Zha, Sensors and Actuators B 111-112, 2 (2005).

17. K. S. Shankar and A. K. Raychaudhuri, Mater. Sci. \& Eng. C 25, 738 (2005).

18. Z. W. Pan, Z. R. Dai and Z. L. Wang, Science 291, 1947 (2001).

19. A. S. Barnard, X. M. Lin and L. A. Curtiss, J. Phys. Chem. B 109, 24465 (2005).

20. O. V. Safonova, R. I. Rumyantseva, R. I. Kozlov, M. Labeau and A. M. Gas'kov, Russ. J. App. Chem. 73, 1322 (2000).

21. G. Tournier and C. Pijolat, Sensors and Actuators B 61, 43 (1999).

22. K. A. Dick, K. Deppert, T. Martensson, B. Mandl, L. Samuelson, W. Seifert, Nano Lett 5, 761 (2005). 